International Journal of Pure and Applied Mathematics

Volume 103 No. 4 2015, 697-707

ISSN: 1311-8080 (printed version); ISSN: 1314-3395 (on-line version)

url: http://www.ijpam.eu

doi: http://dx.doi.org/10.12732/ijpam.v103i4.9

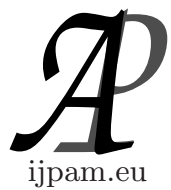

\title{
ON ALMOST WO-CONTINUOUS FUNCTIONS ON ASSOCIATED $w$-SPACES
}

\author{
Young Key Kim ${ }^{1}$, Won Keun $\mathrm{Min}^{2} \S$ \\ ${ }^{1}$ Department of Mathematics \\ MyongJi University \\ Youngin, 449-728, KOREA \\ ${ }^{2}$ Department of Mathematics \\ Kangwon National University \\ Chuncheon, 200-701, KOREA
}

\begin{abstract}
We introduce the notion of almost $W O$-continuity and study some characterizations and properties of such functions. In particular, we study the relation among $W K$-continuity, weakly $W O$-continuity and almost $W O$ continuity.
\end{abstract}

AMS Subject Classification: 54A05, 54B10, 54C10, 54D30

Key Words: $W K$-continuous, almost $W O$-continuous, almost $W O$-open map, weakly $W O$-continuous

\section{Introduction}

In [19], Siwiec introduced the notions of weak neighborhoods and weak base in a topological space. We introduced the weak neighborhood systems defined by using the notion of weak neighborhoods in [13]. And we also introduced a weak neighborhood space (briefly WNS) which is independent of neighborhood spaces [5] and general topological spaces [2]. We introduced the notion of $w$ spaces in [14] and investigated some basic properties. In [15], we introduced and studied the notions $W K$-continuity and $W O$-continuity on associated $w$ -

Received: June 23, 2015

(C) 2015 Academic Publications, Ltd.

$\S_{\text {Correspondence author }}$ url: www.acadpubl.eu 
spaces. In this paper, we introduce the notion of almost $W O$-continuity and study some characterizations and properties of such functions.

\section{Preliminaries}

Let $S$ be a subset of a topological space $X$. The closure (resp., interior) of $S$ will be denoted by $C l(S)$ (resp., Int $(S)$ ). A subset $S$ of $X$ is called a preopen set [11] (resp., $\alpha$-set, $\beta$-open set [15], semi-open [7]) if $S \subset \operatorname{Int}(C l(S)$ ) (resp., $S \subset \operatorname{Int}(C l(\operatorname{Int}(S))), S \subset C l(\operatorname{Int}(C l(S))), S \subset C l(\operatorname{Int}(S$. The complement of a preopen set (resp., $\alpha$-set, $\beta$-open set, semi-open) is called a preclosed set (resp., $\alpha$-closed set, $\beta$-closed set, semi-closed). A subset $A$ of $X$ is said to be quasi $H$-closed relative to $X[20]$ if every collection $\left\{U_{i}: i \in J\right\}$ of open subsets of $X$ such that $A \subset \cup\left\{U_{i}: i \in J\right\}$, there exists a finite subset $J_{0}$ of $J$ such that $A \subset \cup\left\{C l\left(U_{i}\right): i \in J_{0}\right\}$.

A subset $A$ of a topological space $(X, \tau)$ is said to be:

(a) $g$-closed [6] if $C l(A) \subset U$ whenever $A \subset U$ and $U$ is open in $X$;

(b) $g p$-closed [8] if $p C l(A) \subset U$ whenever $A \subset U$ and $U$ is open in $X$;

(c) $g s$-closed [1,4] if $s C l(A) \subset U$ whenever $A \subset U$ and $U$ is open in $X$;

(d) $g \alpha$-closed [10] if $\tau^{\alpha} C l(A) \subset U$ whenever $A \subset U$ and $U$ is $\alpha$-open in $X$ where $\tau^{\alpha}=\alpha(X)$;

(e) $g \alpha^{*}$-closed [9] if $\tau^{\alpha} C l(A) \subset \operatorname{Int}(U)$ whenever $A \subset U$ and $U$ is $\alpha$-open in $X$;

(f) $g \alpha^{* *}$-closed [9] if $\tau^{\alpha} C l(A) \subset \operatorname{Int}(C l(U))$ whenever $A \subset U$ and $U$ is $\alpha$-open in $X$;

(g) $\alpha g$-closed [10] if $\tau^{\alpha} C l(A) \subset U$ whenever $A \subset U$ and $U$ is open in $X$;

(h) $\alpha^{* *} g$-closed [10] if $\tau^{\alpha} C l(A) \subset \operatorname{Int}(C l(U))$ whenever $A \subset U$ and $U$ is open in $X$;

(i) $g$-open (resp., $g p$-open, $g s$-open, $g \alpha$-open, $g \alpha^{*}$-open, $g \alpha^{* *}$-open, $\alpha g$ open,

$\alpha^{* *} g$-open) if the complement $A$ is $g$-closed (resp., $g p$-closed, $g s$-closed, $g \alpha$ closed, $g \alpha^{*}$-closed, $g \alpha^{* *}$-closed, $\alpha g$-closed, $\alpha^{* *} g$-closed).

The family of all $g$-open (resp., $g p$-open, $g s$-open, $g \alpha$-open, $g \alpha^{*}$-open, $g \alpha^{* *}$-open, $\alpha g$-open, $\alpha^{* *} g$-open) sets in $X$ will be denoted by $g O(X)$ (resp., $g p O(X), g s O(X), g \alpha O(X), g \alpha^{*} O(X), g \alpha^{* *} O(X), \alpha g O(X), \alpha^{* *} g O(X)$.

Definition 2.1 ([14]). Let $X$ be a nonempty set. A subfamily $w_{X}$ of the power set $P(X)$ is called a weak structure on $X$ if it satisfies the following:

(1) $\emptyset \in w_{X}$ and $X \in w_{X}$. 
(2) For $U_{1}, U_{2} \in w_{X}, U_{1} \cap U_{2} \in w_{X}$.

Then the pair $\left(X, w_{X}\right)$ is called a $w$-space on $X$. Then $V \in w_{X}$ is called a $w$-open set and the complement of a $w$-open set is a $w$-closed set.

Let $(X, \tau)$ be a topological space. Then the family $\tau, G O(X), g \alpha O(X)$, $g \alpha^{*} O(X), g \alpha^{* *} O(X), \alpha g O(X)$ and $\alpha^{* *} g O(X)$ on $X$ are all weak structures on $X$. But $P O(X), G P O(X)$ and $S O(X)$ are not weak structures on $X$.

Definition $2.2([14])$. Let $\left(X, w_{X}\right)$ be a $w$-space. For a subset $A$ of $X$, the $w$-closure of $A$ and the $w$-interior of $A$ are defined as the following:

(1) $w C l(A)=\cap\left\{F: A \subset F, X-F \in w_{X}\right\}$.

(2) $w \operatorname{Int}(A)=\cup\left\{U: U \subset A, U \in w_{X}\right\}$.

Theorem $2.3([14])$. Let $\left(X, w_{X}\right)$ be a $w$-space and $A \subset X$.

(1) If $A$ is $w$-open, then $w \operatorname{Int}(A)=A$.

(2) If $A$ is $w$-closed, then $w C l(A)=A$.

Theorem $2.4([14])$. Let $\left(X, w_{X}\right)$ be a $w$-space and $A, B \subset X$.

(1) $X=w \operatorname{Int}(X)$ and $\emptyset=w C l(\emptyset)$.

(2) $w \operatorname{Int}(A) \subset A$ and $A \subset w C l(A)$.

(3) $w \operatorname{Int}(A \cap B)=w \operatorname{Int}(A) \cap w \operatorname{Int}(B)$ and $w C l(A \cup B)=w C l(A) \cup w C l(B)$.

(4) $w \operatorname{Int}(w \operatorname{Int}(A))=w \operatorname{Int}(A)$ and $w C l(w C l(A))=w C l(A)$.

(5) $w C l(X-A)=X-w \operatorname{Int}(A)$ and $w \operatorname{Int}(X-A)=X-w C l(A)$.

Let $X$ be a nonempty set and let $(X, \tau)$ be a topological space. A subfamily $w_{\tau}$ of the power set $P(X)$ is called an associated weak structure [15] on $X$ if $\tau \subseteq w_{\tau}$. Then the pair $\left(X, w_{\tau}\right)$ is called an associated $w$-space with $\tau$.

Let $f:\left(X, w_{X}\right) \rightarrow(Y, \mu)$ be a function on an associated $w$-space $\left(X, w_{X}\right)$ and a topological space $(Y, \mu)$. Then $f$ is said to be

(1) weakly WO-continuous [16] if for $x \in X$ and for each open subset $V$ containing $f(x)$, there is a $w$-open subset $U$ containing $x$ such that $f(U) \subset$ $C l(V)$,

(2) WO-continuous [15] if for $x \in X$ and for each open subset $V$ containing $f(x)$, there is a $w$-open subset $U$ of $X$ containing $x$ such that $f(U) \subset V$,

(3) WK-continuous [15] if for every open set $V$ in $Y, f^{-1}(V)$ is a $w$-open set in $X$.

A subset $A$ of a $w$-space $\left(X, w_{X}\right)$ is called $W$-compact [16] relative to $A$ if every collection $\left\{U_{i}: i \in J\right\}$ of $w$-open subsets of $X$ such that $A \subset \cup\left\{U_{i}: i \in\right.$ $J$, there exists a finite subset $J_{0}$ of $J$ such that $A \subset \cup\left\{U_{i}: i \in J_{0}\right\}$. A subset $A$ 
of a $w$-space $\left(X, w_{X}\right)$ is said to be $W$-compact if $A$ is $W$-compact as a subspace of $X$.

\section{Almost $W O$-Continuous Functions}

Definition 3.1. Let $\left(X, w_{X}\right)$ be an associated $w$-space and $(Y, \mu)$ a topological space. Then $f: X \rightarrow Y$ is said to be almost WO-continuous if for $x \in X$ and for each open set $V$ containing $f(x)$, there is a $w$-open set $U$ containing $x$ such that $f(U) \subseteq \operatorname{Int}(C l(V))$.

We get the following implications but the converses are not true from Example 3.2 in [16] and the next example:

continuous $\Rightarrow W K$-continuous $\Rightarrow W O$-continuous $\Rightarrow$ almost WO-continuous $\Rightarrow$ weakly WO-continuous

Example 3.2. In Example 3.2 [16], the function $f$ is almost $W O$-continuous but it is not $W O$-continuous. Next, let $X=\{a, b, c, d, e\}$ and $Y=\{a, b, c, d\}$. Consider a weak structure $w_{X}=\{\emptyset,\{a, b, c\},\{d\},\{e\}, X\}$ and a topological space $\mu=\{\emptyset,\{d\},\{a, b\},\{a, b, d\}, Y\}$. Let $f:\left(X, w_{X}\right) \rightarrow(Y, \mu)$ be a function defined by $f(a)=a, f(b)=b, f(c)=c$ and $f(d)=f(e)=d$. Then $f$ is weakly $W O$-continuous. But for $a \in X$ and $V=\{a, b\}$ containing $f(a)$, there is no any $w$-open set $U$ in $X$ such that $f(U) \subseteq \operatorname{Int}(C l(V))=\{a, b\}$. Hence $f$ is not almost $W O$-continuous.

Theorem 3.3. Let $f: X \rightarrow Y$ be a function on an associated $w$-space $\left(X, w_{X}\right)$ and a topological space $(Y, \mu)$. Then the following statements are equivalent:

(1) $f$ is almost $W O$-continuous at $x \in X$.

(2) $x \in w \operatorname{Int}\left(f^{-1}(\operatorname{Int}(C l(V)))\right)$ for every open set $V$ containing $f(x)$.

(3) $x \in w \operatorname{Int}\left(f^{-1}(V)\right)$ for every regular open set $V$ containing $f(x)$.

(4) For each regular open set $V$ containing $f(x)$, there is a $w$-open set $U$ containing $x$ such that $f(U) \subseteq V$.

Proof. (1) $\Rightarrow(2)$ Let $V$ be any open set in $Y$ containing $f(x)$. By (1), there exists a $w$-open set $U$ of $X$ containing $x$ such that $f(x) \in f(U) \subseteq \operatorname{Int}(C l(V))$. Since $x \in U \subseteq f^{-1}(\operatorname{Int}(C l(V)))$, we have $x \in w \operatorname{Int}\left(f^{-1}(\operatorname{Int}(C l(V)))\right)$. 
(2) $\Rightarrow(3)$ Obvious.

$(3) \Rightarrow(4)$ Let $V$ be any regular open set in $Y$ containing $f(x)$. By (3), it is $x \in w \operatorname{Int}\left(f^{-1}(V)\right)$ and so there exists a $w$-open set $U$ of $X$ containing $x$ such that $x \in U \subseteq f^{-1}(V)$. Thus $f(U) \subseteq V$

$(4) \Rightarrow(1)$ Let $V$ be any open set in $Y$ containing $f(x)$. Then $f(x) \in f(V) \subseteq$ Int $(C l(V))$. Since $\operatorname{Int}(C l(V))$ is regular open, there exists a $w$-open set $U$ of $X$ containing $x$ such that $f(U) \subseteq \operatorname{Int}(C l(V))$. Hence $f$ is almost $W O$-continuous at $x \in X$.

Theorem 3.4. Let $f: X \rightarrow Y$ be a function on an associated $w$-space $\left(X, w_{X}\right)$ and a topological space $(Y, \mu)$. Then the following statements are equivalent:

(1) $f$ is almost $W O$-continuous.

(2) $f^{-1}(V) \subseteq w \operatorname{Int}\left(f^{-1}(\operatorname{Int}(C l(V)))\right)$ for every open set $V$ of $Y$.

(3) $w C l\left(f^{-1}(C l(\operatorname{Int}(F)))\right) \subseteq f^{-1}(F)$ for every closed set $F$ of $Y$.

(4) $w C l\left(f^{-1}(C l(\operatorname{Int}(C l(B))))\right) \subseteq f^{-1}(C l(B))$ for every set $B$ of $Y$.

(5) $f^{-1}(\operatorname{Int}(B)) \subseteq w \operatorname{Int}\left(f^{-1}(\operatorname{Int}(C l(\operatorname{Int}(B))))\right.$ for every set $B$ of $Y$.

(6) $f^{-1}(V)=w \operatorname{Int}\left(f^{-1}(V)\right)$ for every regular open set $V$ of $Y$.

(7) $f^{-1}(F)=w C l\left(f^{-1}(F)\right)$ for every regular closed set $F$ of $Y$.

Proof. (1) $\Rightarrow(2)$ Let $V$ be an open set in $Y$ and $x \in f^{-1}(V)$. There exists a $w$-open set $U$ of $X$ containing $x$ such that $f(U) \subseteq \operatorname{Int}(C l(V))$. Since $x \in$ $U \subseteq f^{-1}(\operatorname{Int}(C l(V)))$, we have $x \in w \operatorname{Int}\left(f^{-1}(\operatorname{Int}(C l(V)))\right)$. Hence $f^{-1}(V) \subseteq$ $w \operatorname{Int}\left(f^{-1}(\operatorname{Int}(C l(V)))\right)$.

$(2) \Rightarrow(3)$ Let $F$ be a closed set in $Y$. Then $Y-F$ in open in $Y$ and, by (2) and Theorem 2.4,

$f^{-1}(Y-F) \subseteq w \operatorname{Int}\left(f^{-1}(\operatorname{Int}(C l(Y-F)))\right)=w \operatorname{Int}\left(f^{-1}(Y-C l(\operatorname{Int}(F)))\right)=$ $X-w C l\left(f^{-1}(C l(\operatorname{Int}(F)))\right)$.

Thus $w C l\left(f^{-1}(C l(\operatorname{Int}(F)))\right) \subseteq f^{-1}(F)$.

$(3) \Rightarrow(4)$ It is obvious.

$(4) \Rightarrow(5)$ Let $B$ be a set of $Y$. Then by (4) and Theorem 2.4,

$f^{-1}(\operatorname{Int}(B))=X-f^{-1}(C l(Y-B)) \subseteq X-w C l\left(f^{-1}(C l(\operatorname{Int}(C l(Y-B))))=\right.$ $w \operatorname{Int}\left(f^{-1}(\operatorname{Int}(C l(\operatorname{Int}(B))))\right.$. Thus we get the result.

$(5) \Rightarrow(6)$ Let $V$ be any regular open set of $Y$. Since $\operatorname{Int}(C l(\operatorname{Int}(V)))=V$, from (5), it follows $f^{-1}(V) \subseteq w \operatorname{Int}\left(f^{-1}(V)\right)$ and so $f^{-1}(V)=w \operatorname{Int}\left(f^{-1}(V)\right.$ ).

$(6) \Rightarrow(7)$ Let $F$ be any regular closed set of $Y$. Then $Y-F$ is any regular open and by (6), we have

$$
X-f^{-1}(F)=f^{-1}(Y-F)=w \operatorname{Int}\left(f^{-1}(Y-F)\right)=X-w C l\left(f^{-1}(F)\right) .
$$


$(7) \Rightarrow(1)$ Let $V$ be any regular open set of $Y$ containing $f(x)$. By (7), $X-f^{-1}(V)=f^{-1}(Y-V)=w C l\left(f^{-1}(Y-V)\right)=X-w \operatorname{Int}\left(f^{-1}(V)\right)$. Since $x \in f^{-1}(V)=w \operatorname{Int}\left(f^{-1}(V)\right)$, there exists a $w$-open set $U$ containing $x$ such that $U \subseteq f^{-1}(V)$. Hence by Theorem 3.3(4), $f$ is almost $W O$-continuous.

Theorem 3.5. Let $f: X \rightarrow Y$ be a function on an associated $w$-space $\left(X, w_{X}\right)$ and a topological space $(Y, \mu)$. Then the following statements are equivalent:

(1) $f$ is almost $W O$-continuous.

(2) $\left.w C l\left(f^{-1}(G)\right)\right) \subseteq f^{-1}(C l(G))$ for every $\beta$-open set $G$ of $Y$.

(3) $\left.w C l\left(f^{-1}(G)\right)\right) \subseteq f^{-1}(C l(G))$ for every semiopen set $G$ of $Y$.

(4) $f^{-1}(G) \subseteq w \operatorname{Int}\left(f^{-1}(\operatorname{Int}(C l(G)))\right)$ for every preopen set $G$ of $Y$.

Proof. $(1) \Rightarrow(2)$ Let $G$ be any $\beta$-open set. Since every $\beta$-open set is regular closed, by Theorem 3.4(7), it is obtained $f^{-1}(C l(G))=w C l\left(f^{-1}(C l(G))\right)$. Thus $\left.w C l\left(f^{-1}(G)\right)\right) \subseteq w C l\left(f^{-1}(C l(G))\right)=f^{-1}(C l(G))$.

$(2) \Rightarrow(3)$ It is obvious since every semiopen set is $\beta$-open.

$(3) \Rightarrow(1)$ Let $F$ be any regular closed set of $Y$; then since $F$ is semiopen, we have $\left.w C l\left(f^{-1}(F)\right)\right) \subseteq f^{-1}(C l(F))=f^{-1}(F)$. Thus from Theorem 3.4(7), it follows $f$ is almost $W O$-continuous.

$(1) \Rightarrow(4)$ Let $V$ be any preopen set of $Y$; then $V \subseteq \operatorname{Int}(C l(V))$ and $\operatorname{Int}(C l(V))$ is regular open, by Theorem 3.4(6),

$$
f^{-1}(\operatorname{Int}(C l(V)))=w C l\left(f^{-1}(\operatorname{Int}(C l(V)))\right) .
$$

Thus we have $f^{-1}(V) \subseteq f^{-1}(\operatorname{Int}(C l(V)))=w C l\left(f^{-1}(\operatorname{Int}(C l(V)))\right)$.

$(4) \Rightarrow(1)$ Let $V$ be any regular open set of $Y$; then $V$ is preopen and $f^{-1}(V) \subseteq w \operatorname{Int}\left(f^{-1}(\operatorname{Int}(C l(V)))\right)=w \operatorname{Int}\left(f^{-1}(V)\right)$.

Hence by Theorem 3.4(6), $f$ is almost $W O$-continuous.

We recall that a point $x$ of a topological space $X$ is said to be $\delta$-cluster point of $A$ if $A \cap \operatorname{Int}(C l(V)) \neq \emptyset$ for every open set $V$ containing $x$. The set of all $\delta$-cluster points of $A$ is called $\delta$-closure of $A$ [20] and is denoted by $C l_{\delta}(A)$. If $A=C l_{\delta}(A)$, then $A$ is called $\delta$-closed. The complement of a $\delta$-closed set is said to be $\delta$-open. It is shown in [20] that $C l(A)=C l_{\delta}(A)$ for every open set $A$ and $C l_{\delta}(B)$ is closed for every subset $B$ of $X$.

Theorem 3.6. Let $f: X \rightarrow Y$ be a function on an associated $w$-space $\left(X, w_{X}\right)$ and a topological space $(Y, \mu)$. Then the following statements are equivalent: 
(1) $f$ is almost $W O$-continuous.

(2) $w C l\left(f^{-1}\left(C l\left(\operatorname{Int}\left(C l_{\delta}(B)\right)\right)\right) \subseteq f^{-1}\left(C l_{\delta}(B)\right)\right.$ for every set $B$ of $Y$.

(3) $w C l\left(f^{-1}(C l(\operatorname{Int}(C l(B)))) \subseteq f^{-1}\left(C l_{\delta}(B)\right)\right.$ for every set $B$ of $Y$.

(4) $w C l\left(f^{-1}(C l(\operatorname{Int}(C l(G)))) \subseteq f^{-1}(C l(G))\right.$ for every open subset $G$ of $Y$.

(5) $w C l\left(f^{-1}(C l(\operatorname{Int}(C l(G)))) \subseteq f^{-1}(C l(G))\right.$ for every preopen subset $G$ of $Y$.

Proof. (1) $\Rightarrow(2)$ Let $B$ be any subset in $Y$; then $C l_{\delta}(B)$ is closed, by Theorem 3.4 (3), we get the result.

$(2) \Rightarrow(3)$ It is obvious since $C l(B) \subseteq C l_{\delta}(B)$ for every subset $B$ of $Y$.

$(3) \Rightarrow(4)$ It is obvious since $C l(G)=C l_{\delta}(G)$ for every open subset $G$ of $Y$.

$(4) \Rightarrow(5)$ Let $G$ be preopen in $Y$; then $C l(G)=C l(\operatorname{Int}(C l(G)))$. By (4),

$w C l\left(f^{-1}(C l(\operatorname{Int}(C l(G))))\right)=w C l\left(f^{-1}(C l(\operatorname{Int}(C l(\operatorname{Int}(C l(G))))))\right.$

$\subseteq f^{-1}(C l(\operatorname{Int}(C l(G))))=f^{-1}(C l(G))$.

$(5) \Rightarrow(1)$ Let $A$ be any regular closed set of $Y$; then since $\operatorname{Int}(A)$ is a preopen set, by (5), we have the following:

$w C l\left(f^{-1}(A)\right)=w C l\left(f^{-1}(C l(\operatorname{Int}(A)))\right)=w C l\left(f^{-1}(C l(\operatorname{Int}(C l(\operatorname{Int}(A)))))\right) \subseteq$ $f^{-1}(C l(\operatorname{Int}(A)))=f^{-1}(A)$. Then $w C l\left(f^{-1}(A)\right)=f^{-1}(A)$ and so by Theorem 3.4(6), $f$ is almost $W O$-continuous.

Theorem 3.7. Let $f: X \rightarrow Y$ be a function on an associated $w$-space $\left(X, w_{X}\right)$ and a topological space $(Y, \mu)$. Then the following statements are equivalent:

(1) $f$ is almost $W O$-continuous.

(2) $f(w C l(A)) \subseteq C l_{\delta}(f(A))$ for every set $A$ of $X$.

(3) $f^{-1}(F)=w C l\left(f^{-1}(F)\right)$ for every $\delta$-closed set $F$ of $Y$.

(4) $f^{-1}(G)=w \operatorname{Int}\left(f^{-1}(G)\right)$ for every $\delta$-open set $G$ of $Y$.

(5) $f^{-1}\left(\operatorname{Int}_{\delta}(B)\right) \subseteq w \operatorname{Int}\left(f^{-1}(B)\right)$ for every set $B$ of $Y$.

(6) $w C l\left(f^{-1}(B)\right) \subseteq f^{-1}\left(C l_{\delta}(B)\right)$ for every set $B$ of $Y$.

Proof. (1) $\Rightarrow(2)$ Let $x \in w C l(A)$ for $A \subseteq X$ and let $V$ be any open set of $Y$ containing $f(x)$. There exists a $w$-open set $U$ containing $x$ such that $f(U) \subseteq \operatorname{Int}(C l(V))$. Since $x \in w C l(A), U \cap A \neq \emptyset$ and so $\emptyset \neq f(U) \cap f(A) \subseteq$ Int $(C l(V)) \cap f(A)$. Thus $f(x) \in C l_{\delta}(f(A))$.

$(2) \Rightarrow(3)$ Let $F$ be any $\delta$-closed set of $Y$. Then $f^{-1}(F)$.

$f\left(w C l\left(f^{-1}(F)\right)\right) \subseteq C l_{\delta}\left(f\left(f^{-1}(F)\right)\right) \subseteq C l_{\delta}(F)=F$. Hence $w C l\left(f^{-1}(F)\right) \subseteq$

$(3) \Rightarrow(4)$ Let $G$ be any $\delta$-open set of $Y$. Then $Y-G$ is a $\delta$-closed set and by (3) and Theorem 2.4, 


$$
X-f^{-1}(G)=f^{-1}(Y-G)=w C l\left(f^{-1}(Y-G)\right)=X-w \operatorname{Int}\left(f^{-1}(G)\right) .
$$
Hence $f^{-1}(G)=w \operatorname{Int}\left(f^{-1}(G)\right)$.

$(4) \Rightarrow(5)$ Let $B$ be any set in $Y$. Then $\operatorname{Int}_{\delta}(B)$ is a $\delta$-open set of $Y$ and so $f^{-1}\left(\operatorname{Int}_{\delta}(B)\right)=w \operatorname{Int}\left(f^{-1}\left(\operatorname{Int}_{\delta}(B)\right)\right) \subseteq w \operatorname{Int}\left(f^{-1}(B)\right)$.

$(5) \Rightarrow(6)$ Let $B$ be a set of $Y$; then from (5) and Theorem 2.4, it follows that

$f^{-1}\left(C l_{\delta}(B)\right)=X-f^{-1}\left(\operatorname{Int}_{\delta}(Y-B)\right) \supseteq X-\left(w \operatorname{Int}\left(f^{-1}(Y-B)\right)\right)=$ $w C l\left(f^{-1}(B)\right)$.

$(6) \Rightarrow(1)$ Let $B$ be a set of $Y$. From $(6)$ and $C l_{\delta}(B)$ is closed in $Y$, we have $w C l\left(f^{-1}\left(\operatorname{Int}\left(C l_{\delta}(B)\right)\right)\right) \subseteq f^{-1}\left(C l_{\delta}\left(\operatorname{Int}\left(C l_{\delta}(B)\right)\right)\right)=f^{-1}\left(C l\left(\operatorname{Int}\left(C l_{\delta}(B)\right)\right)\right) \subseteq$ $f^{-1}\left(C l_{\delta}(B)\right)$. Hence by Theorem 3.6(2), $f$ is almost $W O$-continuous.

Definition 3.8. Let $\left(X, w_{X}\right)$ be an associated $w$-space and $(Y, \mu)$ a topological space. Then $f: X \rightarrow Y$ is said to be almost WO-open if $f(U) \subseteq$ $\operatorname{Int}(C l(f(U)))$ for every $w$-open set $U$ in $X$.

Theorem 3.9. Let $f: X \rightarrow Y$ be a function on an associated $w$-space $\left(X, w_{X}\right)$ and a topological space $(Y, \mu)$. If $f$ is an almost $W O$-open and weakly $W O$-continuous function, then $f$ is almost $W O$-continuous.

Proof. For $x \in X$, let $V$ be an open set containing $f(x)$ in $Y$. Since $f$ is weakly $W O$-continuous, there exists a $w$-open set $U$ containing $x$ such that $f(U) \subseteq C l(V)$. Since $f$ is almost WO-open, $f(U) \subseteq \operatorname{Int}(C l(f(U)))$ and so $f(U) \subseteq \operatorname{Int}(C l(f(U))) \subseteq \operatorname{Int}(C l(V))$. Hence $f$ is almost $W O$-continuous.

A topological space $X$ is said to be

(1) almost-regular [18] if for each regular closed set $F$ of $X$ and each point $x \in X-F$ there exist disjoint open sets $U$ and $V$ of $X$ such that $x \in U$ and $F \subseteq V$

(2) semi-regular [3] if for each open set $U$ of $X$ and each point $x \in U$ there exists a regular open set $V$ of $X$ such that $x \in V \subseteq U$.

Theorem 3.10. Let $f: X \rightarrow Y$ be a function on an associated $w$-space $\left(X, w_{X}\right)$ and a topological space $(Y, \mu)$. If $f$ is almost $W O$-continuous and $Y$ is semi-regular, then $f$ is $W O$-continuous.

Proof. For $x \in X$, let $V$ be an open set containing $f(x)$ in $Y$. Since $Y$ is semi-regular, there exists a regular open set $G$ in $Y$ such that $f(x) \in G \subseteq V$. 
Since $f$ is almost $W O$-continuous, there exists an $w$-open set $U$ containing $x$ such that $f(U) \subseteq \operatorname{Int}(C l(G)) \subseteq V$. Hence $f$ is $W O$-continuous.

Theorem 3.11. Let $f: X \rightarrow Y$ be a function on an associated $w$-space $\left(X, w_{X}\right)$ and a topological space $(Y, \mu)$. If $f$ is weakly $W O$-continuous and $Y$ is almost-regular, then $f$ is almost $W O$-continuous.

Proof. For $x \in X$, let $V$ be an open set containing $f(x)$ in $Y$. Since $Y$ is almost-regular, there exists a regular open set $G$ in $Y$ such that $f(x) \in G \subseteq$ $C l(G) \subseteq \operatorname{Int}(C l(V))$. Since $f$ is weakly $W O$-continuous, there exists an $w$-open set $U$ containing $x$ such that $f(U) \subseteq C l(G) \subseteq \operatorname{Int}(C l(V))$. Hence $f$ is almost $w$-continuous.

Theorem 3.12. Let $\left(X, w_{X}\right)$ be $W$-compact and $(Y, \mu)$ Urysohn. If $f: X \rightarrow Y$ is a weakly WO-continuous surjection, then $f$ is almost WOcontinuous.

Proof. Let $\left\{V_{i}: i \in J\right\}$ be a cover of $Y$ by open subsets of $Y$. For each $x \in X$, there exists $i(x) \in J$ such that $f(x)=y \in V_{i(x)}$. Since $f$ is weakly $W O$ continuous, there exists a $w$-open set $U(x)$ containing $x$ such that $f(U(x)) \subseteq$ $C l\left(V_{i(x)}\right)$. The family $\{U(x): x \in X\}$ is a cover of $X$ by $w$-open sets in $X$. Since $X$ is $w$-compact, there is a finite subcover $\left\{U\left(x_{1}\right), U\left(x_{2}\right), \cdots, U\left(x_{n}\right)\right.$ : $\left.x_{j} \in X, j=1,2, \cdots, n\right\}$ such that $X \subseteq \cup U\left(x_{j}\right)$. Then

$$
Y \subseteq f\left(\cup U\left(x_{j}\right)\right) \subseteq \cup f\left(U\left(x_{j}\right)\right) \subseteq \cup C l\left(V_{i\left(x_{j}\right)}\right),
$$

$1 \leq j \leq n$.

Thus $Y$ is quasi H-closed. Since every quasi H-closed and Urysohn space is almost-regular, by Theorem $3.10, f$ is almost $W O$-continuous.

\section{References}

[1] P. Bhattacharyya and B. K. Lahiri; Semi-generalized closed sets in topology, Indian J. Math., 29(3) (1987), 375-382.

[2] Á. Csázár; Generalized Topology, Generalized Continuity, Acta Math. Hungar., 96 (2002), 351-357.

[3] G. Di Maio and T. Noiri; On s-closed sets spaces, Indian J. Pure Appl. Math., 18(1987), 226-233. 
[4] J. Dontchev and H. Maki; On sg-closed sets and semi- $\lambda$-closed sets, Q \& A in General Topology, 15(1997), 259-266.

[5] D. C. Kent and W. K. Min; Neighborhood Spaces, International Journal of Mathematics and Mathematical Sciences, 32(7) (2002), 387-399.

[6] N. Levine; Generalized closed sets in topology, Rend. Cir. Mat. Palermo, 19(1970), 89-96.

[7] N. Levine; Semi-open sets and semi-continuity in topological spaces, Ams. Math. Monthly, 70(1963), 36-41.

[8] H. Maki, J. Umehara and T. Noiri; Every topological space is pre- $T_{\frac{1}{2}}$, Mem. Fac. Sci. Kochi Univ. Ser. A, 17(1996), 33-42.

[9] H. Maki, R. Devi and K. Balachandran; Associated topologies of generalized $\alpha$-closed sets and $\alpha$-generalized closed sets, Mem. Fac. Sci. Kochi Univ. Ser. A, 15(1994), 51-63.

[10] H. Maki, R. Devi and K. Balachandran; Generalized $\alpha$-closed maps and $\alpha$-generalized closed maps, Indian J. pure appl. Math., 29(1)(1998), 37-49.

[11] A. S. Mashhour, M. E. Abd El-Monsef and S. N. El-Deeb; On precontinuous and weak precontinuous mappings, Proc. Math. and Phys. Soc. Egypt, 53 (1982), 47-53.

[12] W. K. Min; Some Results on Generalized Topological Spaces and Generalized Systems, Acta Math. Hungar., 108 (1-2) (2005), 171-181.

[13] W. K. Min; On Weak Neighborhood Systems and Weak Neighborhood Spaces, Acta Math. Hungar., (2008) DOI:10.1007/s10474-008-7205-8.

[14] W. K. Min and Y. K. Kim; On Weak Structures and w-spaces, Far East Journal of Mathematical Sciences, accepted.

[15] W. K. Min and Y. K. Kim; WO-continuity and WK-continuity On Associated $w$-spaces, International Journal of Pure and Applied Mathematics, accepted.

[16] W. K. Min and Y. K. Kim; Weakly WO-continuous Functions On Associated $w$-spaces, submitted.

[17] O. Njastad; On some classes of nearly open sets, Pacific Journal of Mathematics, 15(3)(1964), 961-970. 
[18] M. K. Singal and S. P. Arya; On almost-regular spaces, Glasnik Mat. III, $4(24)(1969), 89-99$.

[19] F. Siwiec; On Defining a Space by a Weak Base, Pacific Journal of Mathematics, 52(1) (1974), 351-357.

[20] N. V. Velicko, H-closed topological Spaces, Amer. Math. Soc. Transl., 78(1968), 103-118. 
